\title{
Modelling, Simulation and Fuzzy Self-Tuning Control of D-STATCOM in a Single Machine Infinite Bus Power System
}

\author{
Habib Chaib ${ }^{1}$, Tayeb Allaoui ${ }^{1}$, Mustapha Brahami ${ }^{2}$, Mouloud Denai ${ }^{3}$ \\ ${ }^{1}$ Department of Electrical Engineering, Laboratory of Energetic Engineering and Computer Engineering, Ibn Khaldoun \\ University, Tiaret, Algeria. \\ ${ }^{2}$ Department of Electrical Engineering, Laboratory of Intelligent Control and Electrical Power Systems, Djilali Lyabes \\ University, Sidi Bel-Abbes, Algeria.
}

${ }^{3}$ School of Engineering and Technology, University of Hertfordshire, Hatfield, UK.

\begin{abstract}
In recent years, demand for electricity has increased considerably, while the expansion of generation and transmission has been very slow due to limited investment in resources and environmental restrictions. As a result, the power system becomes vulnerable to disturbances and instability. FACTS (Flexible AC Transmission Systems) technology has now been accepted as a potential solution to this problem. This paper deals with the modelling, simulation and fuzzy self-tuning control of a D-STATCOM to enhance the stability and improve the critical fault clearing time (CCT) in a single machine infinite bus (SMIB). A detailed modelling of the D-STATCOM and comprehensive derivation of the fuzzy logic self-tuning control is presented. The dynamic performance of the power system with the proposed control scheme is validated in a simulation study carried out under Matlab/Simulink and SimPowerSystems toolbox. The results demonstrate a significant enhancement of the power system stability under the simulated fault conditions considered.
\end{abstract}

Keywords: critical fault clearing time, D-STATCOM, FACTS, fuzzy self-tuning control, PSS, stability, voltage control

\section{INTRODUCTION}

The energy market has undergone major changes in recent years. Deregulation and new economic constraints have led to a sharp increase in energy exchange between various energy companies. In addition, there has been a growing demand for electric energy especially from countries undergoing industrial expansion. Electric transmission networks have been designed with simple control of energy flow, which often resulted in static and dynamic stability problems. Hence, the control of energy flow in electricity grids is crucial and needs to be addressed to cope with these issues. The exploitation of new opportunities offered by power electronics can now solve the energy flow management problems. These power electronic devices are called FACTS (Flexible Alternative Current Transmission Systems) [1-5].

*Address correspondence to this author at the Department of electrical engineering, Faculty of Applied Sciences, Ibn Khaldoun University, Tiaret, Algeria, email: habib_chaib@hotmail.fr.

They can control power flow by continuous and fast action on the different network settings (phase, voltage, impedance) and can increase the stability margins of power systems and their resulting optimal operation.
FACTS devices can be used for power flow control, voltage regulation, transient stability improvement, and damping of power oscillations. FACTS devices can be shunt or series or a combination of these.

For most practical cases, the insertion of shunt FACTS is much easier than other types of FACTS because it is impossible to open a power line or modify the structure of the electrical network. It has been proved that shunt FACTS devices give maximum benefit due to their stabilized voltage support when connected at the mid-point of the transmission line [2].

One of these power electronic solutions to achieve voltage regulation is the D-STATCOM. The D-STATCOM is a class of custom power devices for providing reliable distribution power quality. It can increase power system stability by damping power oscillations $[1,2,6,7]$.

Several researchers have studied and analysed the different functions of the D-STATCOM $([6,9,11,12,13,14]$, and [16]).

The paper is organised as follows. Section 2 describes the D-STATCOM model and control. The structure and the new design of the D-STATCOM-based damping controller are presented in Section 3. The simulation results and conclusion are presented in Sections 4 and 5 respectively.

2. CONFIGURATION AND MODELING OF THE DSTATCOM 
The D-STATCOM system consists of a voltage source converter (VSC), a control system and coupling reactors (leakage reactance of the transformer). The D-STATCOM produces a controllable AC voltage $\mathrm{V}_{\text {vsc }}$ from the VSC which is connected to a dc link capacitor. The voltage difference between the D-STATCOM bus AC voltage and $\mathrm{V}_{\mathrm{vsc}}$ causes a transfer of active and reactive power between the power system and the D-STATCOM. The voltage at the point of common coupling (PCC) of the power network where the DSTATCOM is connected the voltage is a major concern. All voltages and currents are measured and compared with their respective references, and the resulting error is passed to the controller which then generates a set of switching signals to semiconductor switches (IGBTs) of the power converter [68]. The basic configuration of the D-STATCOM is illustrated in Fig. (1) $[1,2,8,9,10]$.

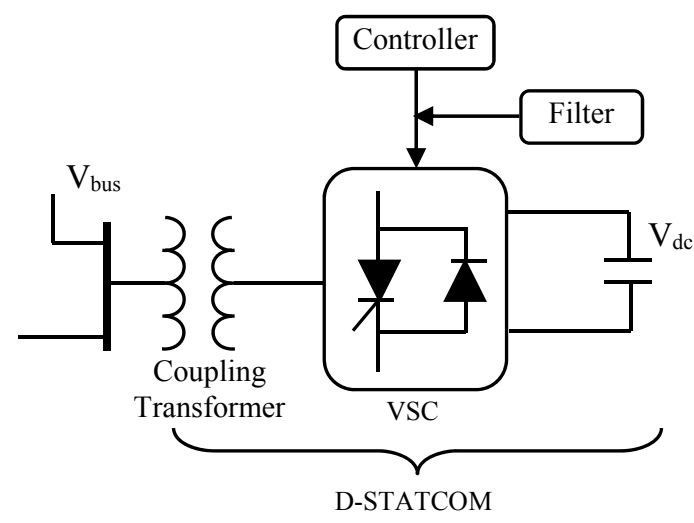

Fig. 1 Basic diagram of the D-STATCOM

In steady state, the voltage VDC is kept constant and with the exception of power losses, there is no real power transfer. However, the reactive power supplied by DSTATCOM is inductive if $\left|\mathrm{V}_{\text {bus }}\right|>\left|\mathrm{V}_{\mathrm{vsc}}\right|$ or capacitive if $\left|\mathrm{V}_{\text {bus }}\right|<\left|\mathrm{V}_{\mathrm{vsc}}\right| \mathrm{D}$ STATCOM provides reactive power to the power system. Thus, the bus voltage can be regulated by the injection or absorption of reactive power [11-16].

The synchronous reference frame method is used to modulate the DSTATCOM in state space.

D-STATCOM consist of dc link capacitor, IGBT based VSC filter and the voltage at the PCC as shown in Fig.(2) $[1,3,7]$.

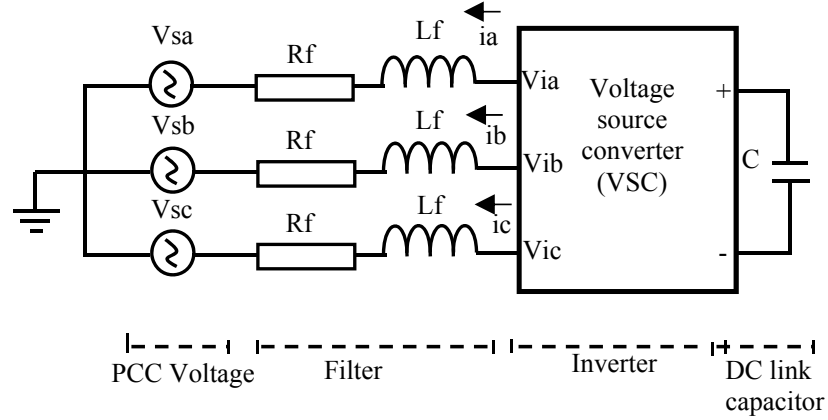

Fig. 2 Basic D-STATCOM equivalent circuit.

$$
\left[\begin{array}{l}
V s a \\
V s b \\
V s c
\end{array}\right]=\sqrt{2 / 3} V_{s}\left[\begin{array}{c}
\sin (\omega t) \\
\sin \left(\omega t-\frac{2 \Pi}{3}\right) \\
\sin \left(\omega t+\frac{2 \Pi}{3}\right)
\end{array}\right]
$$

$\mathrm{V}_{\mathrm{s}}$ is the rms value of the PCC voltage.

The relationship between the inverter output voltage and the PCC voltage is:

$$
\begin{aligned}
& R_{f} i_{a}+L_{f} \frac{d i_{a}}{d t}=V_{S a}-V_{i a} \\
& R_{f} i_{b}+L_{f} \frac{d i_{b}}{d t}=V_{S b}-V_{i b} \\
& R_{f} i_{c}+L_{f} \frac{d i_{c}}{d t}=V_{S c}-V_{i c}
\end{aligned}
$$

Rewriting equations (2) in matrix form.

$$
\frac{d}{d t}\left[\begin{array}{c}
i_{a} \\
i_{b} \\
i_{c}
\end{array}\right]=\left[\begin{array}{ccc}
\frac{-R_{f}}{L_{f}} & 0 & 0 \\
0 & \frac{-R_{f}}{L_{f}} & 0 \\
0 & 0 & \frac{-R f}{L_{f}}
\end{array}\right]\left[\begin{array}{c}
i_{a} \\
i_{b} \\
i_{c}
\end{array}\right]+\frac{1}{L_{f}}\left[\begin{array}{c}
V_{S a}-V_{i d} \\
V_{S b}-V_{i b} \\
V_{S c}-V_{i c}
\end{array}\right]
$$

Using Park's transformation, equation (2) written in synchronous reference frame becomes:

$$
\begin{aligned}
& R_{f} i_{d}+L_{f} \frac{d i_{d}}{d t}=V_{S d}-m V_{D C} \cos \alpha+L_{f} \omega i_{q} \\
& R_{f} i_{q}+L_{f} \frac{d i_{q}}{d t}=V_{S q}+m V_{D C} \sin \alpha-L_{f} \omega i_{d}
\end{aligned}
$$

Where $m$ and $\omega$ are the modulation index of the converter and the system frequency.

Rewriting equations (4) and (5) in matrix form.

$$
\frac{d}{d t}\left[\begin{array}{l}
i_{d} \\
i_{q}
\end{array}\right]=\left[\begin{array}{cc}
\frac{-R_{f}}{L_{f}} & \omega \\
-\omega & \frac{-R_{f}}{L_{f}}
\end{array}\right]\left[\begin{array}{l}
i_{d} \\
i_{q}
\end{array}\right]+\frac{1}{L_{f}}\left(\left[\begin{array}{l}
V_{s d}-V_{i d} \\
V_{s q}-V_{i q}
\end{array}\right]\right)
$$

The harmonics produced by the quadrature and direct axis voltages are negligible.

$$
\begin{aligned}
& V_{i d}=m V_{D C} \cos \alpha \\
& V_{i q}=m V_{D C} \sin \alpha
\end{aligned}
$$

The voltage at the PCC is given as: 
Ideally, $P_{\mathrm{AC}}$ (instantaneous power at the ac terminal $)=P_{\mathrm{DC}}$ (instantaneous power at the dc terminal of the inverter) $[1,7]$, therefore:

$$
V_{D C} I_{D C}=\frac{3}{2}\left(V_{i d} i_{d}+V_{i q} i_{q}\right)
$$

The DC side equation is:

$$
I_{D C}=\frac{3}{2} m\left(i_{d} \cos \alpha+i_{q} \sin \alpha\right)=C \frac{d V_{D C}}{d t}
$$

The mathematical model of D-STATCOM in state space can be written as:

$$
\frac{d}{d t}\left[\begin{array}{c}
i_{d} \\
i_{q} \\
V_{D C}
\end{array}\right]=A\left[\begin{array}{c}
i_{d} \\
i_{q} \\
V_{D C}
\end{array}\right]-\frac{1}{L_{f}}\left[\begin{array}{c}
V_{S d} \\
0 \\
0
\end{array}\right]
$$

Where matrix A is:

$$
A=\left[\begin{array}{ccc}
\frac{-R_{f}}{L_{f}} & \omega & \frac{-m}{L_{f}} \cos \alpha \\
-\omega & \frac{-R_{f}}{L_{f}} & \frac{m}{L_{f}} \sin \alpha \\
\frac{3}{2} m \cos \alpha & \frac{3}{2} \frac{m}{C} \sin \alpha & 0
\end{array}\right]
$$

In the synchronous rotating frame $V_{\mathrm{s}}=V_{\mathrm{sd}}$ and $V_{\mathrm{sq}}=0$, the instantaneous active and reactive powers are:

$$
\begin{aligned}
& Q=\frac{3}{2}\left(V_{S q} i_{d}-V_{S d} i_{q}\right)=-\frac{3}{2} V_{S d} i_{q}=-\frac{3}{2} V_{S} i_{q} \\
& P=\frac{3}{2}\left(V_{S d} i_{d}+V_{S q} i_{q}\right)=\frac{3}{2} V_{S d} i_{d}=\frac{3}{2} V_{S} i_{d}
\end{aligned}
$$

Hence, the performance of the D-STATCOM can be enhanced by controlling the active and reactive components of the currents. This is the so-called PQ-decoupled control [6,7].

At the connection point of the D-STATCOM, the voltage is regulated by absorbing or injecting the reactive power to the bus. Hence two voltage regulators are designed for this purpose, namely DC voltage regulator for the capacitor voltage control and AC voltage regulator for the bus voltage. The regulation of the voltage is achieved through the calculation of $I_{\text {dref }}$ and $I_{\text {qref }}$. The current $I_{\text {dref }}$ is obtained from the error between $V_{\mathrm{dc}}$ and $V_{\mathrm{dc}, \text { ref }}$ through a PI regulator. The current $I_{\text {qref }}$ is obtained by controlling the error between $V_{\text {rms }}(\mathrm{pu})$ and $V_{\text {rms_ref }}(\mathrm{pu})$ using a PI regulator. These reference currents are then regulated by another set of PI regulators whose outputs are the control voltages $V_{\mathrm{d}}$ and $V_{\mathrm{q}}$ for the DSTATCOM as shown in Fig. 3 [1-7].

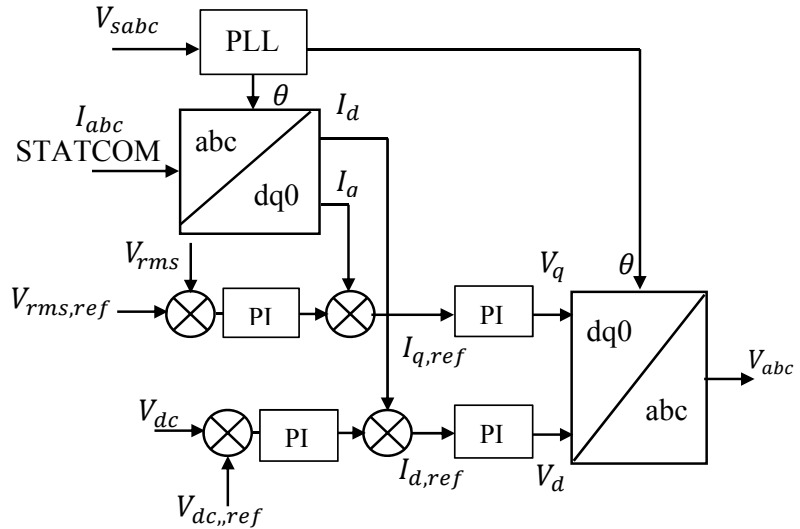

Fig. 3 D-STATCOM control scheme for voltage regulation.

\section{DESIGN OF THE PROPOSED CONTROL} APPROACH

\subsection{D-STATCOM-based Damping Controller}

The structure of the D-STATCOM-based damping controller, to modulate the D-STATCOM injected reactive power is shown in Fig. 4. It consists of a gain block with gain $\mathrm{K}_{\mathrm{D}}$, a signal washout block and two-stage phase compensation block $[2,10,17,18,19]$.

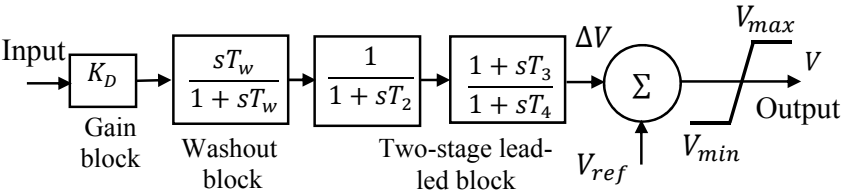

Fig. 4 Structure of the D-STATCOM-based damping controller.

The signal washout block with time constant $T_{\omega}$ serves as a high-pass filter to allow input signals with oscillations to pass unchanged. $T_{\omega}$ value is in the range of 1 to 20 seconds [2, 17-19]. The time constants $T_{2}, T_{3}$ and $T_{4}$ provide the appropriate phase-lead characteristics to compensate for the phase-lag between the input and output signals [2,17,18].

The required compensation is achieved according to the change in the D-STATCOM injected voltage $\Delta V$ which is added to $V_{\text {ref. }}$.

The transfer function of the D-STATCOM-based controller is:

$$
U_{D-\text { STATCOM }}=K_{D}\left(\frac{S T_{\omega}}{1+S T_{\omega}}\right)\left(\frac{1}{1+S T_{2}}\right)\left(\frac{1+S T_{3}}{1+S T_{4}}\right) Y
$$

$U_{\text {D-STADTCOM }}$ and $Y$ are the input and output signals of the DSTATCOM-based controller respectively.

In the present study, the time constants are set to $T_{\omega}=1 \mathrm{~s}$ and $T_{2}=T_{4}=0.002 \mathrm{~s}[2,20,21]$. The controller gain $K_{\mathrm{D}}$ and the time constant $T_{3}$ are to be determined. During transient conditions, the series injected voltage $V$ is modulated to damp system oscillations.

The effective $V$ in dynamic conditions is given by:

$V=V_{r e f}+\Delta V$ 
Following a three-phase fault, oscillations appear due to deviations in the power angle, rotor speed and line power. In this study, the deviation in the line power is chosen as input to the D-STATCOM-based controller. With the variation of the D-STATCOM-based damping controller parameters, these line power deviations will also change.

\subsection{Design of the Fuzzy Self-Tuning Controller}

Fig. 5 shows the basic structure of a fuzzy logic controller (FLC). The inputs are the error $\mathrm{E}$ and the change of error $\mathrm{dE}$ and the output is the gain $\mathrm{K}^{\prime}$ which will tune the $\mathrm{D}$ STATCOM-based controller parameters.

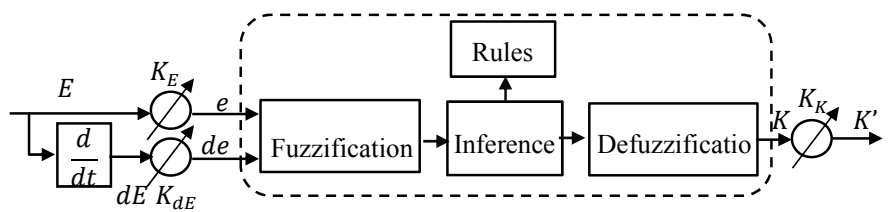

Fig. 5 Bloc diagram of a FLC.

The inputs $(E)$ and $(\mathrm{d} E)$ of the FLC are:

$$
\begin{aligned}
& E=P(\text { power })_{\text {ref }}(k)-P(\text { power })_{\text {mes }}(k) \\
& d E=E(k)-E(k-1)
\end{aligned}
$$

The inputs are represented by three membership functions labelled $\mathrm{N}$ (negative), $\mathrm{Z}$ (zero), $\mathrm{P}$ (positive) and the outputs are labelled with four membership functions labelled $\mathrm{Z}$ (zero), $\mathrm{S}$ (small), M (medium), L (large) as illustrated in Fig. 6.

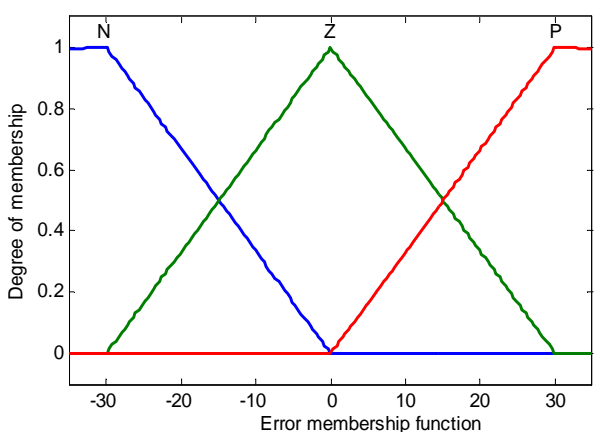

(a)

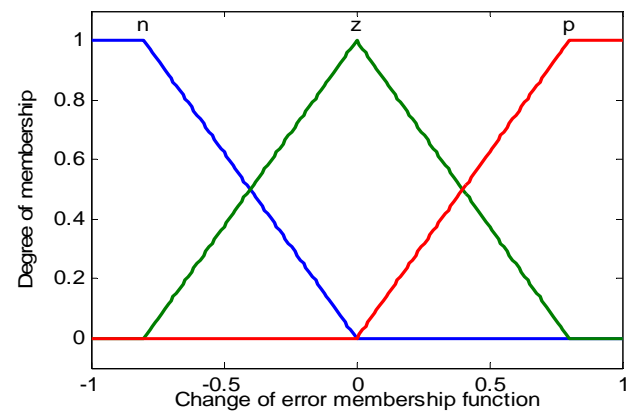

(b)

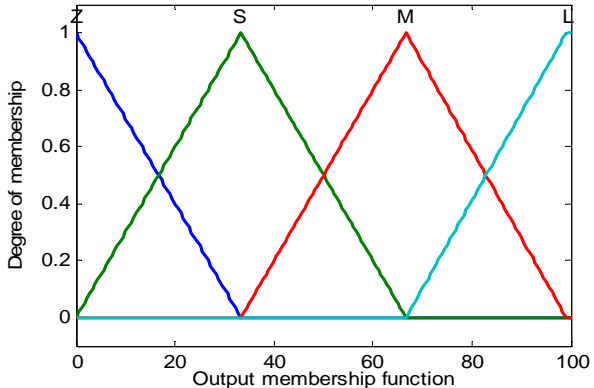

(c)

Fig. 6 Membership functions for: (a) $E$, (b) $\mathrm{d} E$ and (c) $K^{\prime}$.

Table 1 shows the proposed fuzzy rules for the FLC controller.

Table 1 Fuzzy rules.

\begin{tabular}{|c|c|c|c|}
\hline $\mathbf{d E}$ & $\mathbf{E}$ & $\mathbf{Z}$ & $\mathbf{P}$ \\
\hline $\mathbf{N}$ & $\mathrm{Z}$ & $\mathrm{Z}$ & $\mathrm{S}$ \\
\hline $\mathbf{Z}$ & $\mathrm{Z}$ & $\mathrm{Z}$ & $\mathrm{M}$ \\
\hline $\mathbf{P}$ & $\mathrm{Z}$ & $\mathrm{S}$ & $\mathrm{L}$ \\
\hline
\end{tabular}

The centre of gravity method [23] is used for the defuzzification. Therefore, the output $k$ is:

$$
k=\frac{\sum_{i=1}^{n}\left[\mu\left(k_{i}\right) k_{i}\right]}{\sum_{i=1}^{n}\left[\mu\left(k_{i}\right)\right]}
$$

The normalized values of $e$ (error), de (change in error) and output is given by [22-25]:

$$
e=K_{\mathrm{E}} * E, d e=K_{\mathrm{dE}} * d E, K^{\prime}=K_{\mathrm{K}} * k
$$

The FLC was used to calculate $K_{\mathrm{D} \text {-new }}$ and the time constant $T_{3 \text {-new }}$ using a fuzzy self-tuning D-STATCOM controller as shown in Fig. 7.

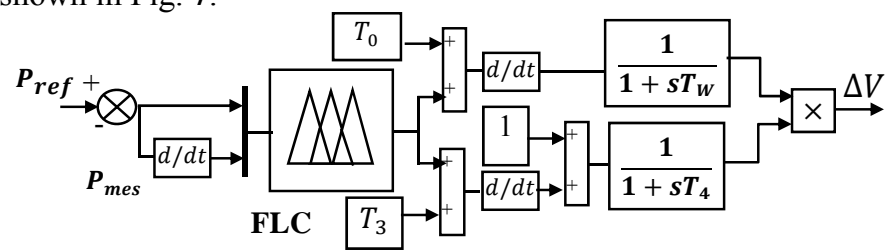

Fig. 7 Fuzzy self-tuning D-STATCOM-based controller

The gain $K^{\prime}$ is continuously updated using the fuzzy algorithm and then used to update the controller gain $K_{\mathrm{D}}$ and time constant $T_{3}$ as indicated in equation (14) [26,27]: 
$K_{\mathrm{D}-\mathrm{new}}=K_{\mathrm{D}}+K^{\prime}$

$T_{3 \text {-new }}=T_{3}+K^{\prime}$

\section{SIMULATION RESULTS AND DISCUSSIONS}

The dynamic performance of the proposed D-STATCOMbased controller is assessed through a series of simulations performed using Matlab/Simulink and SimPowerSystems toolbox. The test system employed to evaluate this control approach is the SMIB power system depicted in Fig. 8. The DSTATCOM device is installed at the mid-point of the transmission line. The parameter values of the system model are given in the Appendix A.

The switching frequency is set to $1300 \mathrm{~Hz}$ and the sampling time $T_{\mathrm{s}}=0.05 \mathrm{msec}$.

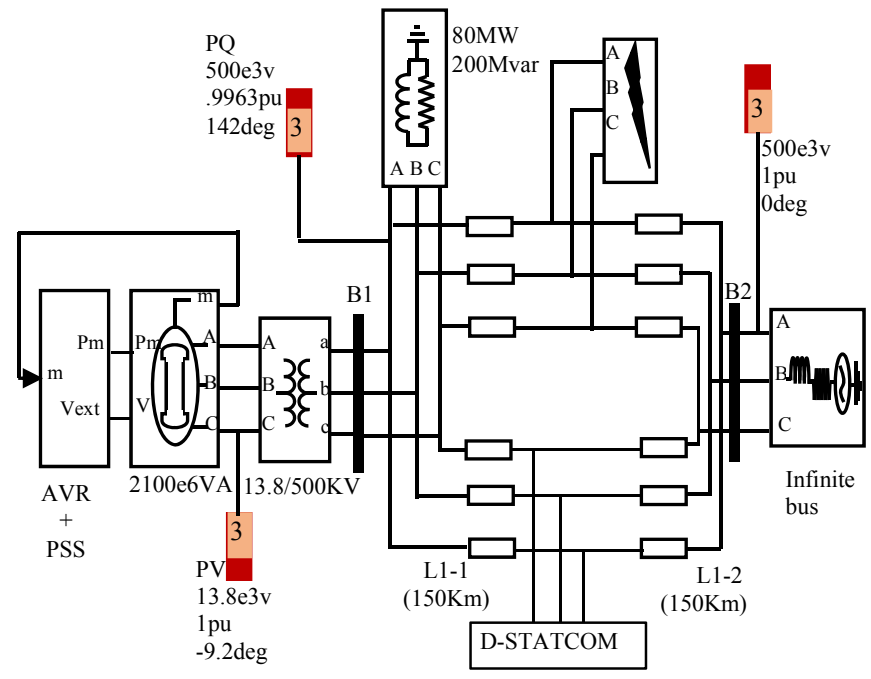

Fig. 8 Single Machine Infinite Bus power system with D-

$$
\text { STATCOM. }
$$

The simulated fault is a three-phase grounded short-circuit on one line as shown in Fig. 8. The fault is located at $150 \mathrm{~km}$ from bus $\mathrm{B} 1$ and is applied at time $t=1 \mathrm{~s}$.

Three case scenarios are studied: The base case corresponds to the original system with only conventional regulation coupled with the generator. The second case, corresponds to the conventional regulation and DSTATCOM-based controller with fixed parameters located at the middle of line 2. Finally, in the last case, both the conventional regulation and fuzzy Self-Tuning DSTATCOM-based controller are used.

\section{a. $\quad$ Test case 0}

The fault is set to occur at $1 \mathrm{~s}$ after the beginning of the simulation. Several tests have been performed in order to determine the fault time for which the system loses its stability. With reference to the red waveforms of Figs. 9 and 10 , the fault time is $256 \mathrm{~ms}$.

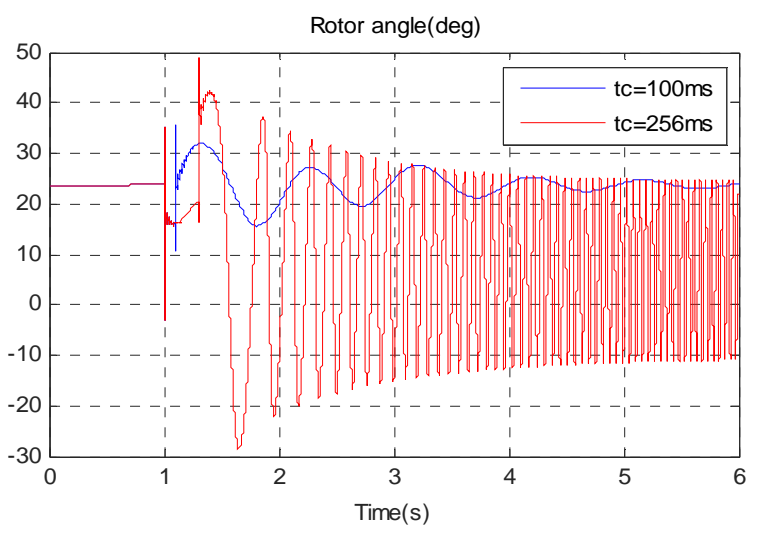

Fig. 9 Rotor angle without regulation. Rotor speed(pu)

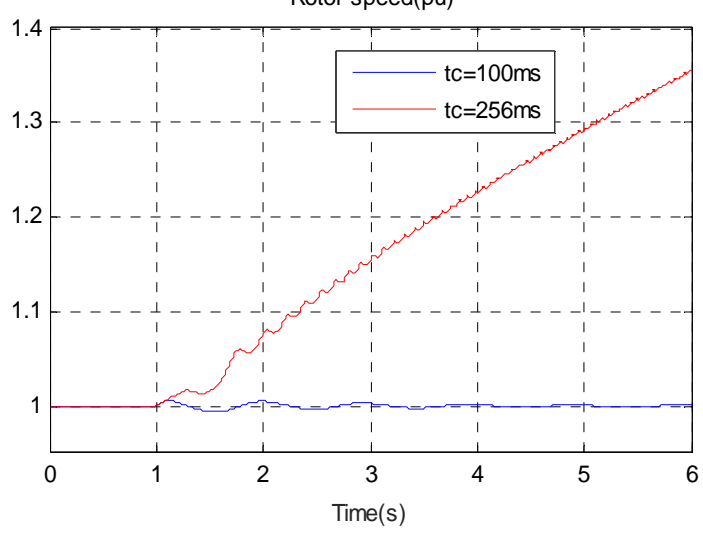

Fig. 10 Rotor speed without regulation.

Simulation results of the rotor angle and the rotor speed deviation of the generators without D-STATCOM are shown in Figs. 9 and 10 respectively. It can be observed that the rotor angle is damped and consequently the system maintains its stability. But when the fault clearing time increased to $256 \mathrm{~ms}$, the rotor angle becomes oscillatory and the rotor speed deviation increases indefinitely. Consequently, the system loses its stability at this critical situation.

\section{b. $\quad$ Test case 1}

To enhance the security margin and improve the power system transient stability, the D-STATCOM-based controller is connected directly at the mid-point of the transmission line.

The behaviour of the network with D-STATCOM-based controller is now simulated for a fault time equal to $256 \mathrm{~ms}$.

The results of Figs. 11 and 12 clearly show the beneficial contribution of the D-STATCOM-based controller in the network stability by improving both the damping of oscillations and the critical fault clearing time. 


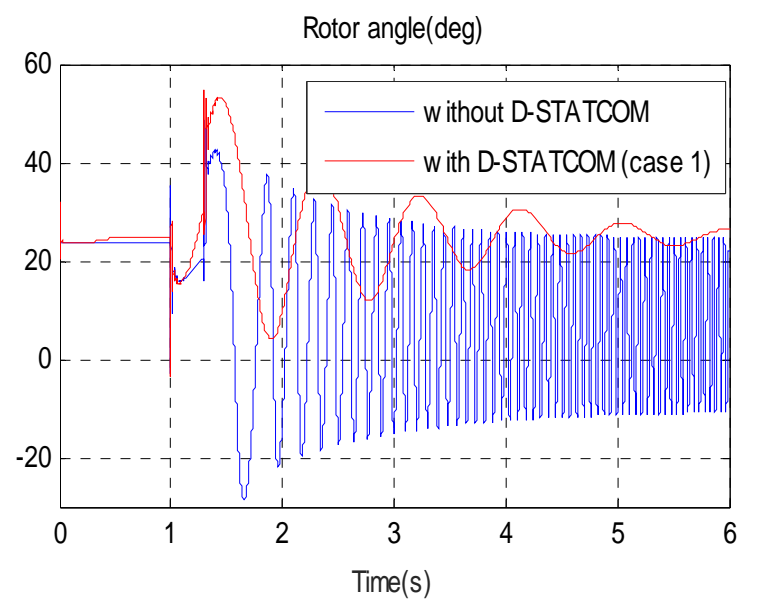

Fig. 11 Rotor angle with and without D-STATCOM.

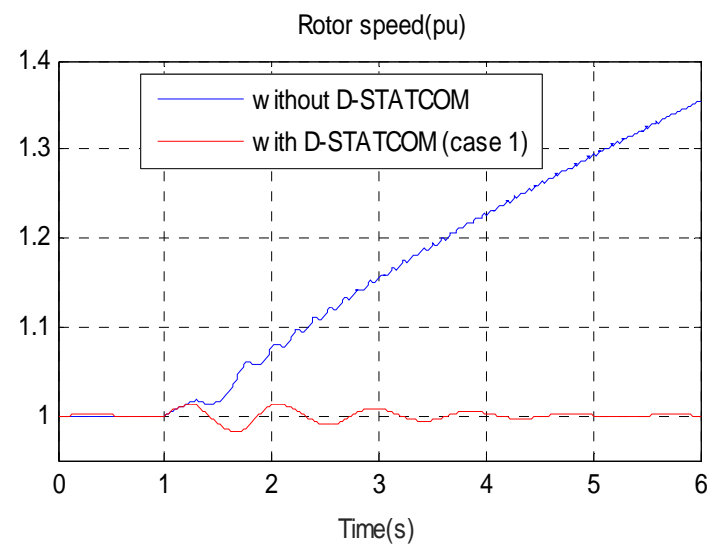

Fig. (12) Rotor speed with and without D-STATCOM.

Fig. 11 shows the response of the DC link voltage.

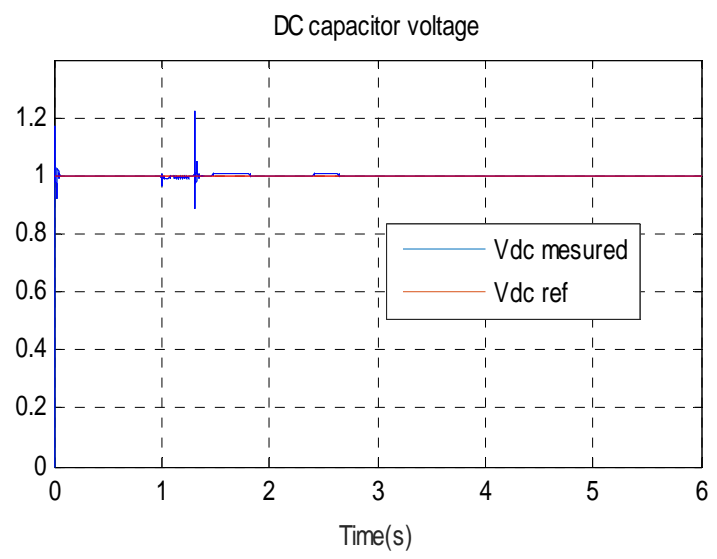

Fig. 13 DC-link voltage of the D-STATCOM.

Fig. 14 shows the response of the regulated voltage at the PCC of the power system.

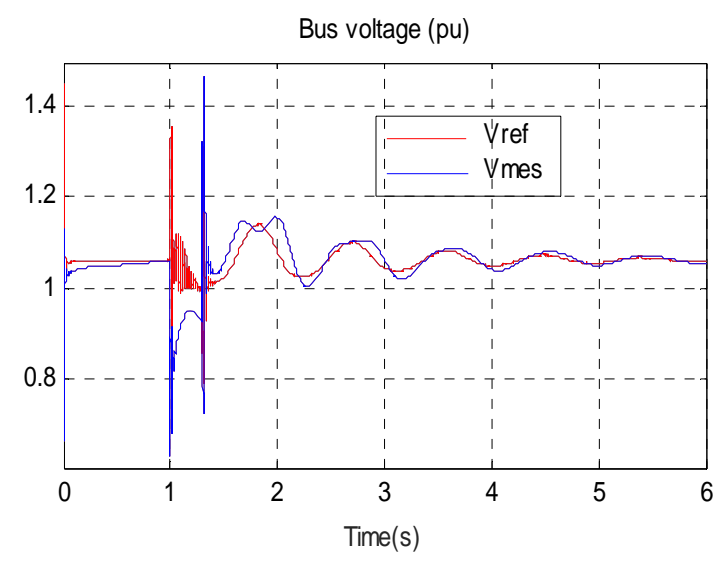

Fig. 14 The regulated PCC voltage

The results of Figs. 13 and 14 demonstrate the good performance provided by the D-STATCOM and the proposed control scheme.

\section{a. $\quad$ Test case 2}

In this simulation scenario, the proposed D-STATCOMbased damping controller is tested.

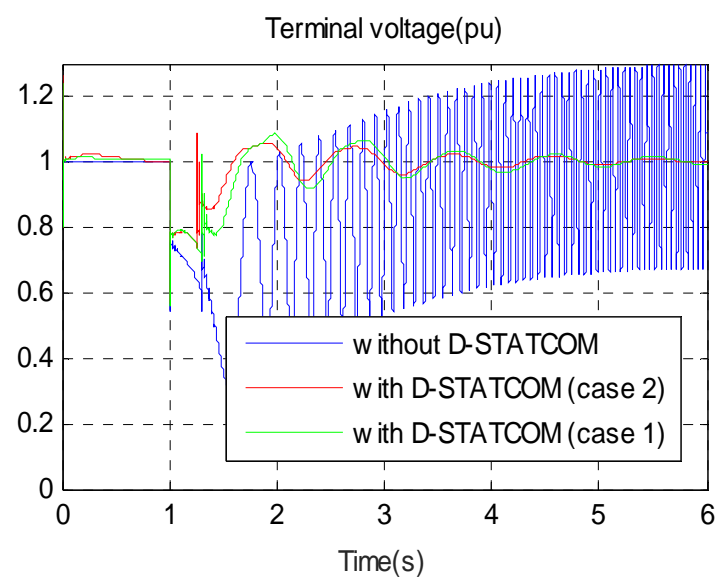

Fig. 15 Terminal voltage.

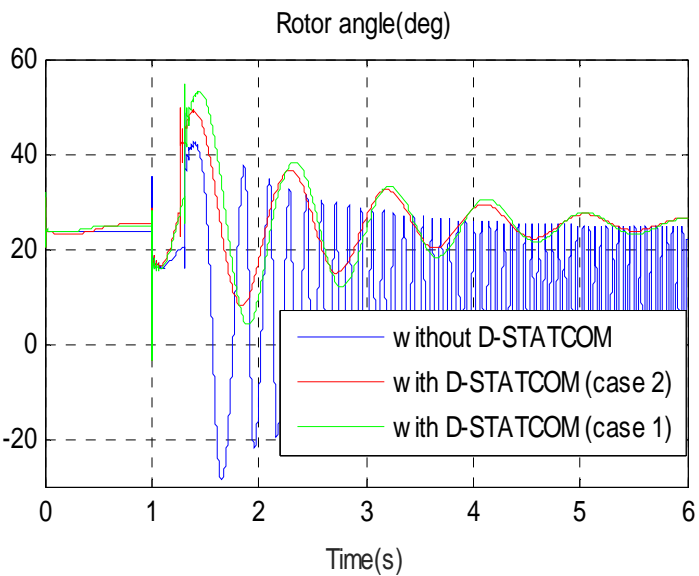

Fig. 16 Rotor angle. 
The results obtained show that the introduction of the novel approach improves the behaviour of the machine characteristics compared with that obtained with case 1 .

\section{CONCLUSION}

The paper proposed a D-STATCOM-based controller using a fuzzy self-tuning approach. This controller proves to be very effective because of its flexibility in controlling several network parameters simultaneously.

The results show that the combined design has an excellent capability in improving the CCT of the power system after the occurrence of a fault, and greatly enhances the dynamic stability of power systems. Moreover, a system performance analysis under different operating conditions and some performance indices studies show the effectiveness of the combined design.

\section{APPENDIX A}

Table A1 Characteristics of the generator.

\begin{tabular}{|l|l|}
\hline Rated apparent power (MVA) & 1000 \\
\hline $\mathrm{V}_{\text {base }}(\mathrm{kV})$ & 500 \\
\hline $\mathrm{F}_{\mathrm{n}}(\mathrm{Hz})$ & 60 \\
\hline $\mathrm{H}(\mathrm{s})$ & 3.7 \\
\hline $\mathrm{X}_{\mathrm{d}}(\mathrm{pu})$ & 1.305 \\
\hline $\mathrm{X}_{\mathrm{q}}(\mathrm{pu})$ & 0.474 \\
\hline $\mathrm{X}_{\mathrm{d}}{ }_{\mathrm{d}}(\mathrm{pu})$ & 0.296 \\
\hline $\mathrm{X}_{\mathrm{q}}{ }_{\mathrm{q}}(\mathrm{pu})$ & 0.296 \\
\hline Stator resistance $(\mathrm{pu})$ & $2.8544 \times 10^{-3}$ \\
\hline Number of pairs of poles & 32 \\
\hline
\end{tabular}

Table A2 characteristics of lines.

\begin{tabular}{|l|l|l|l|l|}
\hline $\begin{array}{l}\text { Line i- } \\
\mathrm{j}\end{array}$ & $\mathrm{R}(\Omega / \mathrm{km})$ & $\mathrm{L}(\mathrm{mH} / \mathrm{km})$ & $\mathrm{C}(\mathrm{nF} / \mathrm{km})$ & $\mathrm{L}(\mathrm{km})$ \\
\hline $2-3$ & 0.02546 & 0.9337 & 12.74 & 300 \\
\hline
\end{tabular}

Table A3 D-STATCOM parameters.

\begin{tabular}{|c|l|l|l|l|}
\hline $\operatorname{vdc}(\mathrm{V})$ & $\mathrm{r}(\Omega)$ & $\mathrm{L}(\mathrm{mH})$ & $\mathrm{S}(\mathrm{Hz})$ & $\operatorname{Vdc}(\mathrm{v})$ \\
\hline 300 & 0.01 & 0.1 & 1250 & 300 \\
\hline
\end{tabular}

\section{APPENDIX B}

- Current regulation of D-STATCOM (sliding mode).

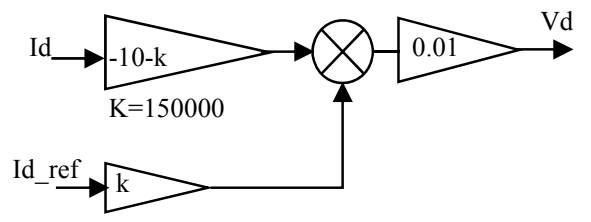

- $\quad$ DC voltage regulation (sliding mode):

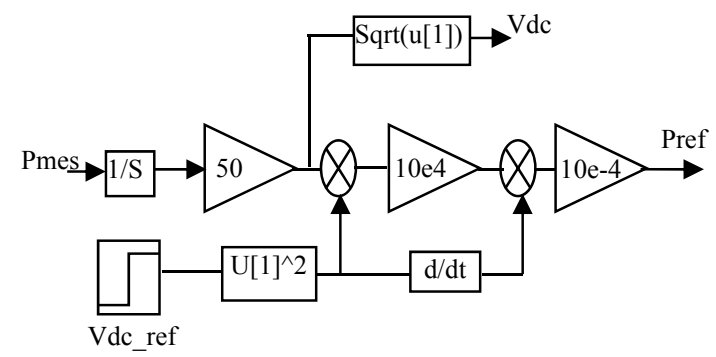

\section{REFERENCES}

[1] Hingorani, N.G.; Gyugyi, L. Understanding FACTS: Concepts and Technology of Flexible AC Transmission Systems .IEEE Press, New York, 2000.

[2] Kundur, P. Power System Stability and Control. New York, McGraw- Hill Book Company, 1994.

[3] Gholipour ; Saadate,S. Improving of Transient Stability of Power Systems Using UPFC. IEEE transactions on power delivery, vol. 20, no.2, April 2005.

[4] D. Ruiz-Vega; M. Glavic; D. Ernst. Transient stability emergency control combining open-loop and closed-loop techniques. IEEE PES General Meeting 2003, Toronto, Canada, 2003

[5] M. Pavella; D. Ernst; D. Ruis-Vega. Transient stability of power systems: a unified approach to assessment and control. Kluwer Academic Publisher, 2000.

[6] Akil, A.; Sayyad, N. Simulation of d-statcom in power system. Journal of Electrical and Electronics Engineering, e-ISSN: 22781676, p-ISSN: 2320-3331 PP 01-08, 2014.

[7] Farhad,S.; Sumedha R.; Arindam G. Static Compensators (STATCOMs) in Power Systems; springer: New York, September 2014.

[8] Aman,G.; Ratna,D.; Singh, G. K. A Comparison of Novel Optimal Fuzzy and LMI Based Wide Area Controller for Stability Enhancement with STATCOM. Proceedings of RAECS UIET Panjab University Chandigarh, 06 - 08 March, 2014.

[9] Sensarma, P. S.; Padiyar, K. R.; Ramanarayanan,V. Analysis and Performance Evaluation of a Distribution STATCOM for Compensating Voltage Fluctuations. IEEE TRANSACTIONS ON POWER DELIVERY, VOL. 16, NO. 2, APRIL 2001.

[10] Abido, M.A. Analysis and assessment of STATCOM-based damping stabilizers for power system stability enhancement. Electric Power Systems Research 73 (2005), pp 177-185.

[11] Bhim, S.; Jayaprakash, P.; Kothari, D. P.;Ambrish, C.; Kamal Al H. Comprehensive Study of DSTATCOM Configurations. IEEE transactions on industrial informatics, Vol 10, No 2, May 2014.

[12] Claudio, A. Can,i.; Massimo, P.; Sandro, C.; Edvina, U. STATCOM modeling for voltage and angle stability studies. Electrical Power and Energy Systems 25 (2003), pp 431-441. 
[13] Arindam, G.; Gerard, L. Load compensating dstatcom in weak ac systems. IEEE transactions on power delivery, Vol 18, No 4, October 2003

[14] Chandan, K.; Mahesh, K.M. A Multifunctional DSTATCOM Operating Under Stiff Source. IEEE transactions on industrial electronics, Vol 61, No 7, July 2014.

[15] Chandan, K.; Mahesh, K.M. Marco, L. Design of External Inductor for improving performance of Voltage Controlled DSTATCOM. IEEE transactions on industrial electronics DOI 10.1109/TIE.2016.2552148P

[16] Sharad, S.P.; Deshpande, A.P.; Meera, M. Modelling and Simulation of DSTATCOM for Power Quality Improvement in Distribution System Using MATLAB Simulink Tool. 2015 International Conference on Energy Systems and Applications (ICESA 2015) summer meeting, Vol 2, Vancouver, Canada, 15-19 July 2001, pp 755-760.

[17] Abdel-Magid, Y. L.; Abido, M. A.; AI-Baiyat, S.; Mantawy A. H. simultaneous stabilization of multimachine power systems via genetic algorithms. IEEE Transactions on Power Systems, Vol 14, No 4, November 1999.

[18] Mak, L.O.; Ni, Y.X.; Shen, C.M. STATCOM with fuzzy controllers for interconnected power systems. Electric Power Systems Research 55 (2000), pp 87-95.

[19] Larsen, E.V.; Swam, D.A. Applying Power System Stabilizers Part I: General Concepts. IEEE Transactions on Power Apparatus and Systems, vol. PAS-100, No.6, June 1981, pp 3017-3024.

[20] Trudnowski, D.; Smith, J.; Short, T.; Pierre, D. An application of prony methods in PSS design for multimachine systems. IEEE Trans-PWRS 6 (1) 1991.
[21] Hussain, A. N.; Malek, F.; Rashid,M. A.; Haji Abd Malek, M. F. Performance Improvement of Power System Stability by Using Multiple Damping Controllers Based on PSS and the UPFC. International Journal of Engineering and Technology, Vol 5 No 4 Aug-Sep 2013.

[22] Choi, B-J.; Kwak, S-W.; Kim, B.K. Design and stability analysis of single-input fuzzy logic controller, IEEE Transactions on Systems, Man and Cybernetics, Vol. 30, No. 2 (2000).

[23] M. F. Bugallo; V. Elvira; L. Martino; D. Luengo; J. Miguez; P. M.Djuric. Adaptive Importance Sampling: The Past, the Present, and the Future. IEEE Signal Processing Magazine, Vol 34, lssue 4, pp 60-79, 2017.

[24] Tzung-Pei, H.; Chai-Ying, L. Induction of fuzzy rules and membership functions from training examples. Fuzzy Sets and Systems 84 (1996), pp $33-47$.

[25] Jains, K.; Agrawal, P.; Gupta, HO. Fuzzy logic controlled shunt active power filter for power quality improvement. IEE. Proc. Eletrcr. Power Appl., Vol 149, No 5, pp.317-328, 2002.

[26] Ting, W.; Jian-Feng, Y.; Qing, M. DC Side Ripple Voltage Analysis and Fuzzy PI Control Strategy Research for APF. The Open Electrical \& Electronic Engineering Journal, 2015, 9, pp 263-272.

[27] Mudi, R. K.; Pal, N. R. A robust self-tuning scheme for PI and PD type fuzzy controllers. IEEE Trans. Fuzzy Systems, Vol 7, pp. 2-16, Feb.1999. 